\title{
EQUILIBRIUM AND KINETIC PARAMETERS FOR THE SEDIMENTATION OF TARTARIC SALTS IN YOUNG WINES
}

\author{
Ecaterina Covaci ${ }^{a^{*}}$, Gheorghe Duca ${ }^{\mathrm{b}}$, Rodica Sturza ${ }^{\mathrm{c}}$ \\ anstitute of Chemistry of Academy of Sciences of Moldova, 3, Academiei str., Chisinau MD-2028, Republic of Moldova \\ ${ }^{b}$ Academy of Sciences of Moldova, 1, Stefan cel Mare str., Chisinau MD-2001, Republic of Moldova \\ ${ }^{c}$ Technical University of Moldova, 168, Stefan cel Mare str., Chisinau MD-2004, Republic of Moldova \\ "e-mail: covaci_ecaterina@yahoo.com; phone: (+373) 69305475
}

\begin{abstract}
In young wines potassium hydrogen tartrate is always present in supersaturating concentration and crystallizes spontaneously. The aim of this study is to obtain kinetic parameters, which explain the stability of young wines during the stabilization treatments. The kinetic and equilibrium parameters were evaluated and discussed. The heating factor has a decisive influence on the reaction rate of potassium hydrogen tartrate precipitation in young wines. An increase of temperature leads to a decrease in efficiency of stabilization process and to an enhancement of the activation energy of the system. According to the obtained experimental results, the optimal regime for production and stabilization of young wines has been established.
\end{abstract}

Keywords: kinetic parameters, young wines, crystalline stabilization, Arrhenius plots.

Received: February 2015/ Revised final: April 2015/Accepted: April 2015

\section{Introduction}

The presence of tartaric salts, potassium hydrogen tartrate (KHT) and calcium tartrate (CaT) is one of the main causes of wines instability. The wine differs in the retention capacity for tartaric salts in solution. If the holding capacity is exceeded, these salts will precipitate, resulting in the formation of tartrate casse or tartaric precipitation [1]. Generally, the solubility of potassium hydrogen tartrate primarily depends on the alcohol content, the value of $\mathrm{pH}$, the temperature of the wine, the presence of colloids and the interactive effects of various cations and anions. In young wines, KHT is always present in supersaturating concentrations and crystallizes spontaneously [2].

Nowadays, several treatments are used prior to wine bottling in order to prevent the precipitation of tartaric salts. Physical treatments consists in promoting the crystallization by cooling the wine to $-4^{\circ} \mathrm{C}$ and subsequent removal of tartaric salts by filtration or elimination of the potassium and tartaric ions by electro-dialysis or by the use of ionexchange resins $[3,4]$. The used for the treatment of young wines cooling techniques have found a commercial application. These techniques are characterized by long term (weeks), the wine conservation being carried out at temperature below freezing, to encourage the tartrates to crystallize and precipitate out of the wine [5].

The precipitation of KHT in wine follows a second-order kinetics reaction between the bitartrate ion (HT) and the potassium ion $\left(\mathrm{K}^{+}\right)$, briefly expressed in kinetic notations [6]:

$$
\begin{aligned}
& H T+K^{+} \leftrightarrow K H T \\
& \begin{array}{llll}
A & B & X
\end{array}
\end{aligned}
$$

The KHT crystallization process occurs in two stages: nucleation phase and growing of nucleus into crystals. In the second stage crystal growth occurs, when the KHT ions migrate to the active sites on the surface of the seed crystals and are incorporated into a crystal lattice. If, for some reason, the active sites on the crystal surface are blocked (due to adsorption of colloids), crystal growth is impeded. Certain present in wine phenolic compounds and polysaccharides have been shown to impede crystal growth. Also, it is important to note that nucleation occurs in a supersaturated solution with the KHT concentration at a critical level. Below this level (such as e.g. in the case of slightly supersaturated wine) nucleation will be slow. It is because of the thermodynamics involved, that it requires a long time for the solution to change from supersaturation to a reasonably stable state [7]. Thus, the efficiency of cold stabilization (the wine cooling performed in interval -4 to $-10^{\circ} \mathrm{C}$ ) is caused by decrease of the tartaric salts solubility, which determines the creation of an interface between the two phases, a process that requires a lot of interface energy [8]. This step can be accelerated by the addition of cream of tartar (crystal of potassium tartrate), which has the role of crystallization initiator. The addition of KHT crystals eliminates the nuclei induction phase and this speeds up the time that is required to stabilize the wine. Once formed, the crystals grow and then can be removed by filtration leaving a stable towards KHT wine [9].

The KHT precipitation may be elucidated by using a thermodynamic model [10], but a kinetic model is another useful tool to explain the mechanism of processes. The present contribution is aimed at determination the equilibrium and kinetic parameters of the tartaric precipitation in young wines in order to elucidate the mechanism of KHT precipitation at different concentration of colloidal systems. To the best of our knowledge, this is the first report about the use of potassium hydrogen tartrate for study of kinetic parameters for the precipitation from a natural solution (white and red young wines). These parameters describe the kinetics of stabilization, the precipitation process at different temperature and the KHT concentrations are evaluated and discussed. 


\section{Experimental}

Investigations have been conducted on two young wines that were obtained from Chardonnay and Pinot Noir varieties of vintage 2014. Experiments were carried out during September-December 2014, at the Oenology Research Centre of Technical University of Moldova and the National Audit Centre of Alcoholic Products, Chisinau, Republic of Moldova. The presence of proteins and polyphenolic compounds can exhibit a holding capacity for tartaric acid, thus inhibiting KHT formation, as set forth in Introduction [7]. In order to minimize the influence of complex agents and colloidal substances on KHT precipitation, the wine should be clarified by fining agents and filtration, before chilling and cold storage. Fouling of KHT crystals occurs when, during the crystallization processes, certain colloidal substances occupy the active sites on the crystal surface and, as a result, halt crystal growth. The fouling substances include certain pigments, polyphenols, proteins, and polysaccharides. The extent of crystal fouling depends on the amount and types of present in wine colloidal substances. Pre-treatment of wine, such as clarification, fining and filtration reduce the level of colloidal material and thus minimize the fouling of KHT crystals that is important for its reuse [11]. For this purpose, the Chardonnay grapes variety was vinified by two technological schemes: the classical scheme (sample 1) and the application of gluing treatments before fermentation with bentonite and cryo-maceration of the marc (sample 2). The similar treatments were also carried out for the Pinot Noir grape variety, such as classic winemaking (sample 3) and carbonic maceration of grains (sample 4).

Application of bentonite $(0.3 \mathrm{~g} / \mathrm{kg}$ grapes $)$ and cryo-maceration of the marc allowed the reduction of oxidative enzyme activity by an average of $20 \%$, as well as decrease of protein and phenolic substances content [12]. Moreover, these products have medium color intensity, high content of varietal and secondary aromas and organoleptic characteristic of the variety. During carbonic maceration the intracellular maceration of integral grains in normal atmosphere occurs, which promotes the major diffusion of the substances from the peel to the core by changing the permeability of tissues and cell wall (biological phenomena) [13].

After the completion of alcoholic fermentation, the wine samples have been decanted and settled in order to ensure the colloidal stability. Then tartaric stabilization of the wines samples was performed by two methods: conventional cold stabilization or chill-proofing and static contact seeding with $5 \mathrm{~g} / \mathrm{L} \mathrm{KHT}$ at the temperature of $-5^{\circ} \mathrm{C}$ [14]. The gluing agent for white wine was bentonite of Super type [15] at doses $0.75 \mathrm{~g} / \mathrm{L}$ and gelatin of Pulviclar S type [16] at $0.35 \mathrm{~g} / \mathrm{L}$. After the stabilization by the above-mentioned procedures, the wine samples were filtrated at the seeding temperature, to avoid resolubilization of potassium bitartrate crystals into wine. Physico-chemical analyses of the wine have been evaluated by the alcohol content, the total acidity, the $\mathrm{pH}$ value, the content of tartaric acid, potassium and others, using the presented in national and international standards methods [17]. The content of cations in wines before and after the tartaric stabilization were determined via the recommended by International Organization of Vine and Wine (IOVV) method, using atomic absorption spectrometry and the content of organic acids - by capillary electrophoresis. The obtained data were used to calculate the progress, the rate and the Arrhenius parameters of the reaction, according to the proposed by methodology $[18,19]$.

\section{Results and discussion}

The data of the main wine composition characteristics, before and after the stabilization, are presented in Tables 1 and 2. According to them, the color intensity and the total polyphenol index diminished in the limits of $23 \div 40 \%$ of initial values, during the tartaric stabilization of wine samples.

Table 1

Physico-chemical characteristics of white wines.

\begin{tabular}{|c|c|c|c|c|c|c|}
\hline \multirow[b]{2}{*}{ Parameters } & \multicolumn{3}{|c|}{ Sample 1 of white wine } & \multicolumn{3}{|c|}{ Sample 2 of white wine } \\
\hline & 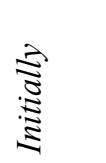 & 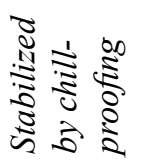 & 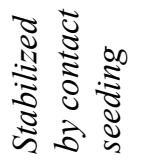 & 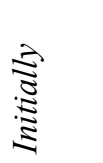 & 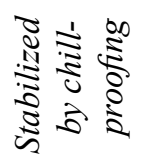 & 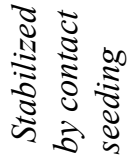 \\
\hline Ethanol $( \pm 0.06 \% \mathrm{v} / \mathrm{v})$ & 12.62 & 12.48 & 12.48 & 12.42 & 12.22 & 12.22 \\
\hline $\mathrm{pH}( \pm 0.01)$ & 3.13 & 3.08 & 3.06 & 3.27 & 3.13 & 3.11 \\
\hline Total acidity in tartaric acid, $( \pm 0.04 \mathrm{~g} / \mathrm{L})$ & 7.82 & 6.80 & 6.72 & 7.94 & 6.90 & 6.86 \\
\hline Content of tartaric acid $( \pm 0.01 \mathrm{~g} / \mathrm{L})$ & 2.60 & 1.62 & 1.58 & 2.25 & 1.46 & 1.41 \\
\hline Content of potassium $( \pm 0.002 \mathrm{~g} / \mathrm{L})$ & 0.920 & 0.713 & 0.682 & 0.846 & 0.643 & 0.613 \\
\hline Color intensity, $\mathrm{A}_{420 \mathrm{~nm}}( \pm 0.001)$ & 0.092 & 0.048 & 0.042 & 0.089 & 0.054 & 0.052 \\
\hline Total polyphenol index $(\mathrm{TPI})( \pm 0.02 \mathrm{mg} / \mathrm{L})$ & 148.8 & 86.3 & 82.5 & 132.5 & 88.1 & 86.4 \\
\hline Conductivity at $20^{\circ} \mathrm{C}( \pm 1 \mu \mathrm{S} / \mathrm{cm})$ & 1988 & 1670 & 1620 & 1813 & 1510 & 1530 \\
\hline Organoleptic analysis ( \pm 0.1 points) & 7.7 & 7.8 & 7.8 & 8.0 & 8.0 & 8.1 \\
\hline
\end{tabular}


The content of tartaric acid and potassium ions in samples has also decreased in the following order: $37.64 \%$ and $25 \%$ for samples of white wines and $26.24 \%$ and $41.14 \%$ for red ones, correspondingly. The electrical conductivity during the stabilization has diminished an average of $15.9 \%$ and the treatments of young wines enhance the aroma expression, the flavor persistence and specific color for this type of wine in organoleptic terms.

Table 2

Physico-chemical characteristics of red wines.

\begin{tabular}{|c|c|c|c|c|c|c|}
\hline \multirow[b]{2}{*}{ Parameters } & \multicolumn{3}{|c|}{ Sample 3 of red wine } & \multicolumn{3}{|c|}{ Sample 4 of red wine } \\
\hline &  & 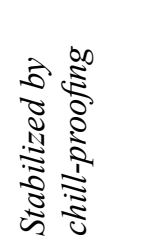 &  & $\begin{array}{l}\vec{\nabla} \\
: \vec{\Xi} \\
\stackrel{\Xi}{\Xi}\end{array}$ & 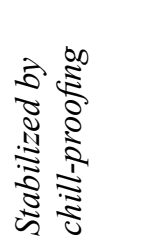 & 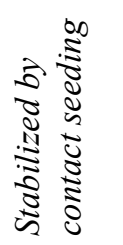 \\
\hline Ethanol $( \pm 0.06 \% \mathrm{v} / \mathrm{v})$ & 10.25 & 10.20 & 10.20 & 10.15 & 10.00 & 10.00 \\
\hline $\mathrm{pH}( \pm 0.01)$ & 3.30 & 3.20 & 3.22 & 3.12 & 3.04 & 3.05 \\
\hline Total acidity in tartaric acid $( \pm 0.04 \mathrm{~g} / \mathrm{L})$ & 8.43 & 7.62 & 7.61 & 7.85 & 7.0 & 7.1 \\
\hline Content of tartaric acid $( \pm 0.01 \mathrm{~g} / \mathrm{L})$ & 2.07 & 1.48 & 1.46 & 2.0 & 1.52 & 1.54 \\
\hline Content of potassium $( \pm 0.002 \mathrm{~g} / \mathrm{L})$ & 1.071 & 0.612 & 0.614 & 0.734 & 0.454 & 0.432 \\
\hline Color intensity $( \pm 0.001)$ & 1.483 & 1.121 & 1.134 & 0.864 & 0.612 & 0.642 \\
\hline Total polyphenol index (TPI) $( \pm 0.02 \mathrm{mg} / \mathrm{L})$ & 1498.1 & 1158.3 & 1142.7 & 692.7 & 422.6 & 411.5 \\
\hline Conductivity at $20^{\circ} \mathrm{C}( \pm 1 \mu \mathrm{S} / \mathrm{cm})$ & 2066 & 1735 & 1702 & 1920 & 1800 & 1770 \\
\hline Organoleptic analysis ( \pm 0.1 points) & 7.8 & 7.9 & 7.9 & 8.0 & 8.1 & 8.1 \\
\hline
\end{tabular}

The applied schemes have a positive impact upon the KHT precipitation, compared to the traditional method of winemaking in examined wine samples. This effect is described by reducing the content of ions HT by $14.29 \%$ and $8.09 \%$ of $\mathrm{K}^{+}$for sample 2 and $3.62 \%$ and $31.39 \%$ for the sample 4 , respectively. The comparative analysis of the two procedures revealed that decrease of all parameters is more significant in the case of contact seeding procedure, in comparison with conventional cold stabilization.

The determination of equilibrium and kinetic parameters for the sedimentation of tartaric salts was possible through the study of the reaction rate at different temperatures and stabilization time, which allowed describing the process by Arrenius equation for the studied wines.

\section{Effect of stabilization time on the kinetic parameters}

The solubility of KHT diminishes essentially at lower temperature that facilitates its crystallization and precipitation into wines. The KHT precipitation rate is dependent on the chemical composition of the reaction medium and the duration of treatment. On the basis of the tartaric acid and potassium ions content at a temperature of $268 \mathrm{~K}$, the kinetic parameters which describe the process of KHT precipitation in all wine samples there were calculated. The terms, which are used in the calculation of rate constant $(k)$ and the reaction rate $(\mathrm{dCx} / \mathrm{d} \tau)$, are the following:

$$
\begin{aligned}
& k=\frac{1}{\tau(C a-C b)} \ln \frac{C b(C a-C x)}{C a(C b-C x)} \\
& -\frac{d C x}{d \tau}=k(C a-C x)(C b-C x)
\end{aligned}
$$

In order to find the prevalent compounds at the equilibrium stage, the equilibrium constants of reaction (1) were calculated, whose values are in the range $17.75-22.48$ for the white samples and $18.96-29.63$ for the red samples, respectively. The dominance of the reaction products in the system at equilibrium stage is marked by a higher value of $k$ to unity, allowing the subsequent calculation of the evolution of kinetic parameters at different temperatures and stabilization time. The value of parameters that describe the reaction progress and the rate for two samples of wine are given in Table 3. Calculations were carried out at different steps of the reaction, until obtaining the constant values of the studied parameters. 
From the Table 3, the amount of precipitated KHT is almost the same for the white wine samples by an average of $3.42 \mathrm{~mol}^{2} \cdot \mathrm{L}^{-2} \cdot 10^{5}$ and $4.61-2.24 \mathrm{~mol}^{2} \cdot \mathrm{L}^{-2} \cdot 10^{5}$ for the red ones, respectively. The positive impact of technological schemes was achieved by the increase of KHT rate precipitation with an average of $4.8 \%$ for studied wine samples.

Table 3

The concentrations of reactants species and the rate of process at different stages of the reaction ( $T=268 \mathrm{~K}$, the process of conventional cold stabilization).

\begin{tabular}{|c|c|c|c|c|c|}
\hline \multirow[t]{2}{*}{ Type of wine } & \multirow{2}{*}{$\begin{array}{c}\text { The reaction } \\
\text { step }\end{array}$} & \multicolumn{3}{|c|}{ Average concentrations of reactants species } & \multirow{2}{*}{$\begin{array}{c}\text { The reaction rate, } \\
\mathrm{mol} \cdot \mathrm{L}^{-1} \cdot \mathrm{h}^{-1} \cdot 10^{7}\end{array}$} \\
\hline & & $\begin{array}{c}H T \\
\mathrm{~mol} \cdot \mathrm{L}^{-1} \cdot 10^{2}\end{array}$ & $\begin{array}{c}K^{+}, \\
\mathrm{mol} \cdot \mathrm{L}^{-1} \cdot 10^{2}\end{array}$ & $\begin{array}{c}\mathrm{KHT} \\
\mathrm{mol}^{2} \cdot \mathrm{L}^{-2} \cdot 10^{5}\end{array}$ & \\
\hline \multirow{5}{*}{$\begin{array}{c}\text { Sample } 1 \\
\text { of white wine }\end{array}$} & $\tau_{0}$ & 1.75 & 2.35 & - & - \\
\hline & $\tau_{1 / 4}$ & 1.60 & 2.26 & 0.131 & 0.35 \\
\hline & $\tau_{1 / 2}$ & 1.37 & 2.06 & 1.089 & 1.05 \\
\hline & $\tau_{2 / 3}$ & 1.19 & 1.92 & 2.352 & 3.35 \\
\hline & $\tau_{\text {eq }}$ & 1.07 & 1.84 & 3.495 & 4.44 \\
\hline \multirow{5}{*}{$\begin{array}{c}\text { Sample } 2 \\
\text { of white wine }\end{array}$} & $\tau_{0}$ & 1.5 & 2.16 & - & - \\
\hline & $\tau_{1 / 4}$ & 1.40 & 2.14 & 0.026 & 0.75 \\
\hline & $\overline{\tau_{1 / 2}}$ & 1.27 & 2.05 & 0.268 & 1.11 \\
\hline & $\tau_{2 / 3}$ & 1.13 & 1.84 & 2.172 & 3.59 \\
\hline & $\tau_{\mathrm{eq}}$ & 1.04 & 1.49 & 3.349 & 4.64 \\
\hline \multirow{5}{*}{$\begin{array}{l}\text { Sample } 3 \\
\text { of red wine }\end{array}$} & $\tau_{0}$ & 1.38 & 2.74 & - & - \\
\hline & $\tau_{1 / 4}$ & 1.27 & 2.36 & 0.431 & 2.16 \\
\hline & $\tau_{1 / 2}$ & 1.13 & 2.18 & 1.409 & 3.48 \\
\hline & $\tau_{2 / 3}$ & 1.08 & 1.98 & 2.294 & 4.64 \\
\hline & $\tau_{\text {eq }}$ & 0.99 & 1.57 & 4.606 & 5.73 \\
\hline \multirow{5}{*}{$\begin{array}{l}\text { Sample } 4 \\
\text { of red wine }\end{array}$} & $\tau_{0}$ & 1.33 & 1.88 & - & - \\
\hline & $\tau_{1 / 4}$ & 1.29 & 1.83 & 0.019 & 1.21 \\
\hline & $\tau_{1 / 2}$ & 1.19 & 1.59 & 0.389 & 2.04 \\
\hline & $\tau_{2 / 3}$ & 1.13 & 1.381 & 0.998 & 3.48 \\
\hline & $\overline{\tau_{\mathrm{eq}}}$ & 1.01 & 1.17 & 2.241 & 5.89 \\
\hline
\end{tabular}

With the aim of elucidation the optimal method of stabilizing both the processes (conventional cold and contact seeding stabilization), the comparative evolution of kinetic parameters has been studied in wine samples under the same conditions of stabilization. Evolution of reaction and its rate for young white and red wine are similar, as representatively shown for sample 2 in Figure 1.

From the presented in Figure 1 diagram it is evident that the level of KHT precipitation process is practically constant (with slight variations) for both applied processes throughout the stabilization. A growth of 0.1 to $0.25 \cdot 10^{-5} \mathrm{~mol} \cdot \mathrm{L}^{-1}$ occurs at the contact process, in comparison with the classic one. The second calculated parameter, the rate of reaction, is strongly influenced by the contact process that determines a major difference between the two applied methods. At the beginning of contact stabilization, the rate of formation and KHT precipitation in wine is by 4-5 times higher compared to the classical process at $268 \mathrm{~K}$, and then halve in the final stages. This can be explained by the addition of cream of tartar, which initiates formation of KHT micro-crystals in wine volume. As a result, the period of wine stabilization is significantly reduced, as representatively displayed in Figure 2.

Using the contact method of stabilization, the reduction of stabilization period with 30 hours for sample 1 and 23 hours for sample 3 was obtained, in comparison with chill-proofing stabilization method (Figure 2). Samples 2 and 4 require a stabilization period of 8 and 15 hours, respectively, which is shorter as compared to control samples (samples 1 and 3), using the same stabilization method. This fact may be explained by the presence of macromolecules that inhibit the tartaric salts agglomeration in the wine. Thus, the produced by two technological schemes wines (samples 2 and 4) contain $18-23 \%$ less protein and colloidal substances, when compared to the control sample, which explains the increasing trend of the reaction rate. 
In conclusion, we recommend the cryo- and carbonic maceration as technological schemes for the production of young wines and stabilization by contact seeding, in order to achieve young wines with pronounced organoleptic characteristics.

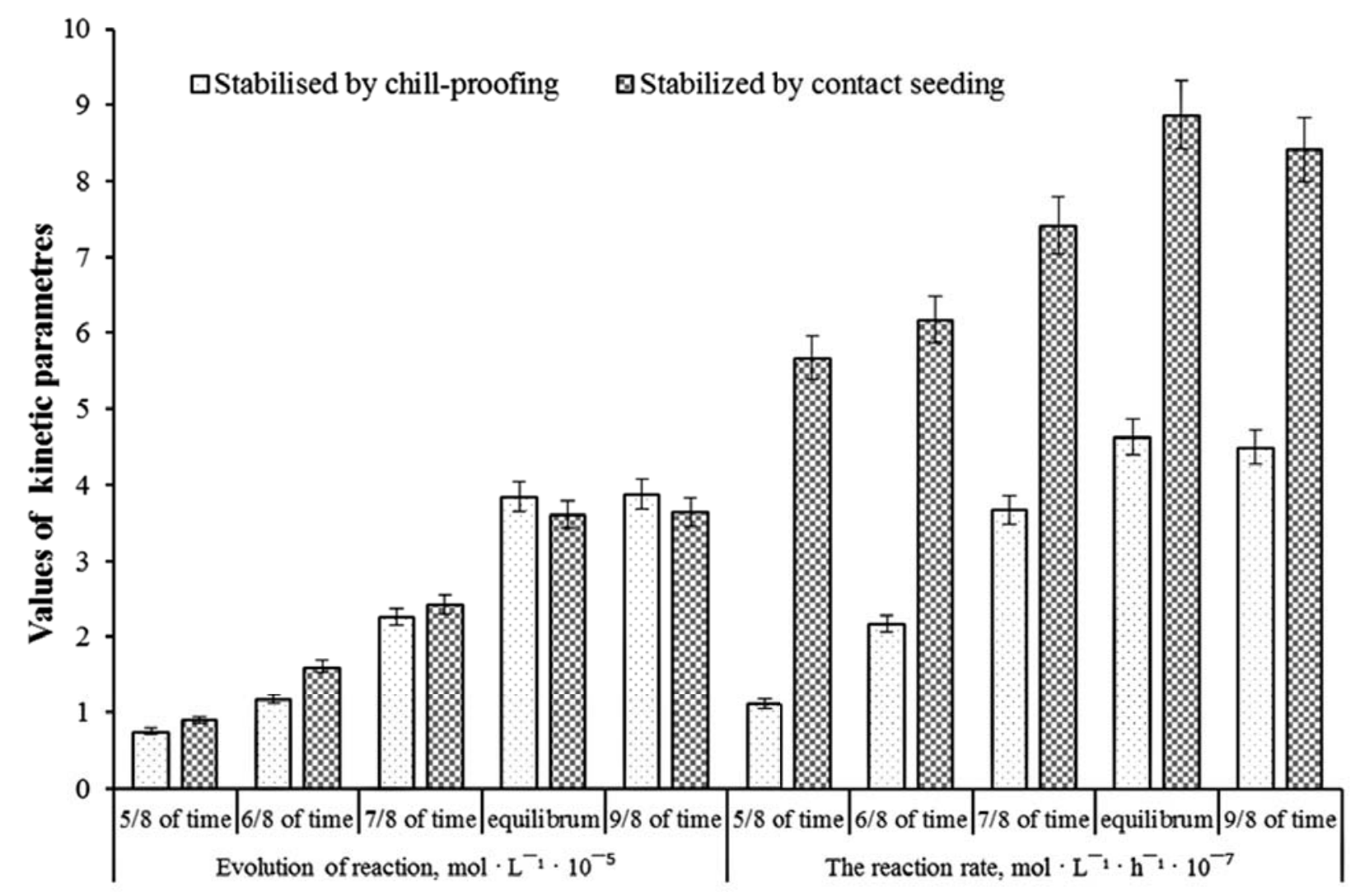

Figure 1. Evolution of reaction and its rate as a function of stabilization time (sample 2, $\mathbf{T}=\mathbf{2 6 8} \mathrm{K}$ ).



Figure 2. Time of stabilization the wine samples, depending on the applied process $(\mathrm{T}=\mathbf{2 6 8} \mathrm{K})$.

\section{Effect of temperature on the kinetic parameters}

As it is well known, temperature and storage time that is necessary to stabilize a wine, depend on the kind of wine. The thermal factor is determinative on the process for KHT precipitation in wine, because it determines its solubility. The kinetic parameters of precipitation the potassium hydrogen tartrate at temperatures of 268,273 and $278 \mathrm{~K}$ are presented in Figure 3. 


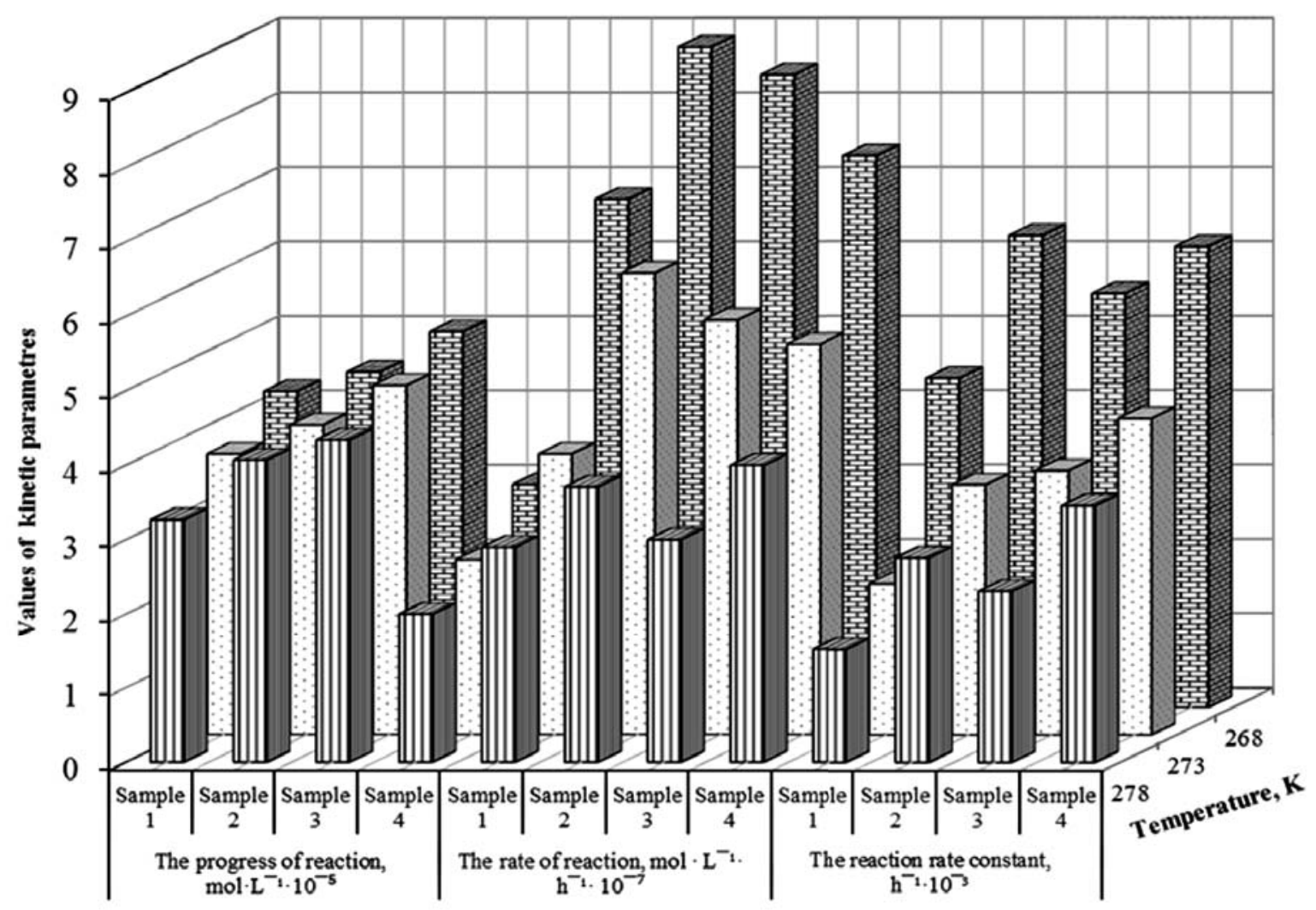

Figure 3. Values of the kinetic parameters of potassium hydrogen tartrate precipitation at different temperatures (sample 1 is stabilized by contact seeding).

From the presented in Figure 3 diagram, the increase of temperature causes significant decreasing of kinetic parameter values, such as rate and rate constant, and for reaction advancing the amendment is minor. Temperature fluctuations during cold stabilization have a significant effect for reducing the rate of KHT precipitation, due to the effect on the speed of nuclei formation. The temperature dependence of the parameters was determined, through the mathematical calculations [20]. The increasing of temperature with ratio 5 (arithmetic progression) determines the regression with ratio 3 of rate reaction in examined wine samples.

In order to optimize the tartaric stabilization process, we studied at the same time both the influence of temperature and stabilization time on the values of reaction rate in wine samples. The correlation between reaction rate and stabilization time at different temperatures for sample 2 is shown in Figure 4.

The presented in Figure 4 histogram shows a relative rising trend up to $62.5 \%$ of the stabilization time, followed by a significant increasing until reaching the final equilibrium and a slight decreasing of values at the end of process. Throughout the stabilization, the reaction rate has maximum values at $268 \mathrm{~K}$ and minimum at $278 \mathrm{~K}$. Taking into account the afore-presented considerations (Figures 2 and 3), sample 2 can be stabilized by contact seeding at $273 \mathrm{~K}$ to preserve its native character and to reduce the financial costs of the wine stabilization.

Mathematical processing of the results, according to Jäntschi L. [21], allowed determining the dependence of the reaction rate on both factors (Table 4). Rate of the process linearly depends by a polynom of 4 orders on the treatment temperature and stabilization time. In the achieved calculations, Pearson correlation coefficient $\left(\mathrm{R}^{2}\right)$ has values within the limits $0.9866 \div 0.9975$, which shows the correctness of selected functions and that the variance of $y$ is attributed to the relation existing between $x$ and $y$.

Table 4

The regression equation and the correlation coefficient of precipitation rate constant for sample 2 , stabilized by conventional cold stabilization method.

Temperature, $K \quad$ The regression equation The correlation coefficient

\begin{tabular}{lll}
\hline 268 & $Y=-3 E-07 x^{4}+6 E-05 x^{3}-0.0034 x^{2}+0.0612 x-0.0189$ & 0.9947 \\
\hline 273 & $Y=-3 E-07 x^{4}+6 E-05 x^{3}-0.0036 x^{2}+0.0603 x-0.0078$ & 0.9975 \\
\hline 278 & $Y=-1 E-07 x^{4}+3 E-05 x^{3}-0.0012 x^{2}+0.0175 x-0.0088$ & 0.9866 \\
\hline
\end{tabular}




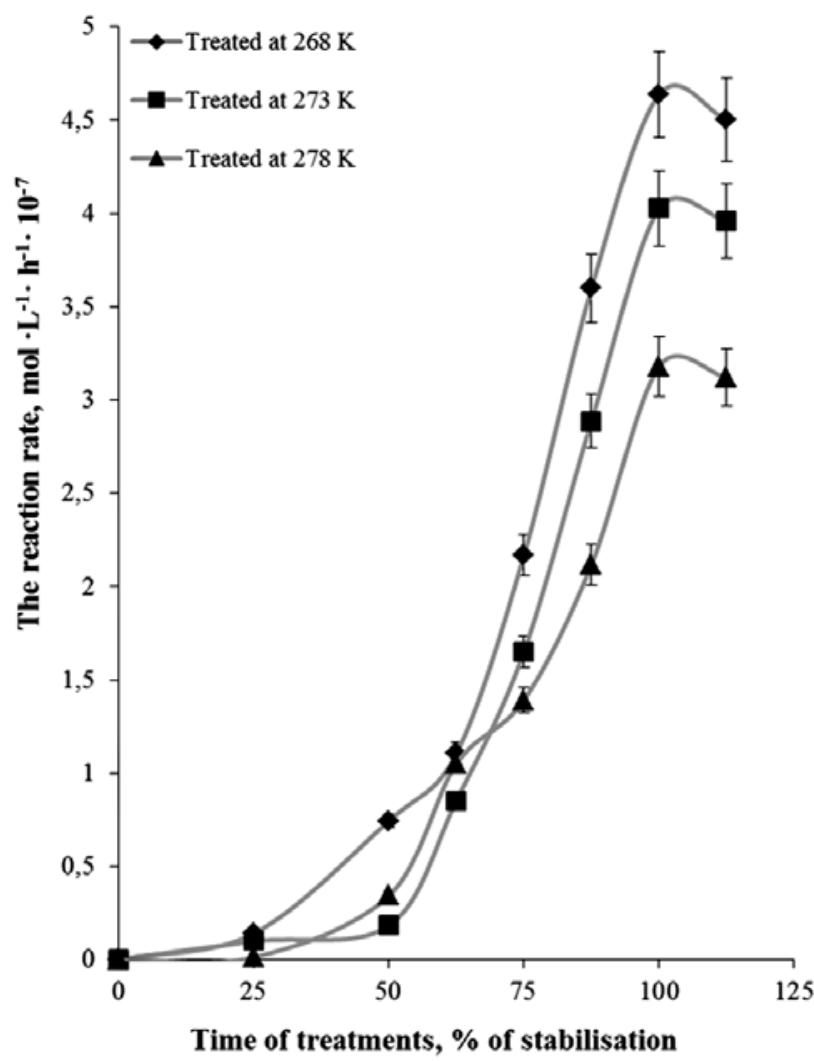

Figure 4. Values of the potassium hydrogen tartrate precipitation rate at different temperatures (sample 2 stabilized by conventional cold stabilization).

In conclusion, the values of kinetic parameters diminish with increasing of temperature, indicating on the exothermic character of KHT precipitation and this trend is presented for all samples of wine. Temperature and wine composition have a major influence on the reaction rate. The rate of KHT precipitation is greater at lower temperatures than at higher temperatures in the examined wines containing $10-12 \%$ alcohol.

\section{Kinetic parameters of activation}

The KHT precipitation can be summarized by a reversible process, which may be elucidated by using a kinetic model for explanation the mechanism that occurs during this process. In order to determine the Arrhenius parameters of the reaction, graphics of dependence $\ln k=\mathrm{f}(1000 / \mathrm{T})$ at 268,273 and $278 \mathrm{~K}$ temperatures were built (Figure 5). In the achieved calculations, the reaction rate constant $(k)$ logarithm is represented as a straight line function of $1 / \mathrm{T}$ of KHT precipitation in acid medium and its correlation coefficients were observed to be highest $\left(\mathrm{R}^{2}=0.9842-0.9867\right)$ in examined white wine.

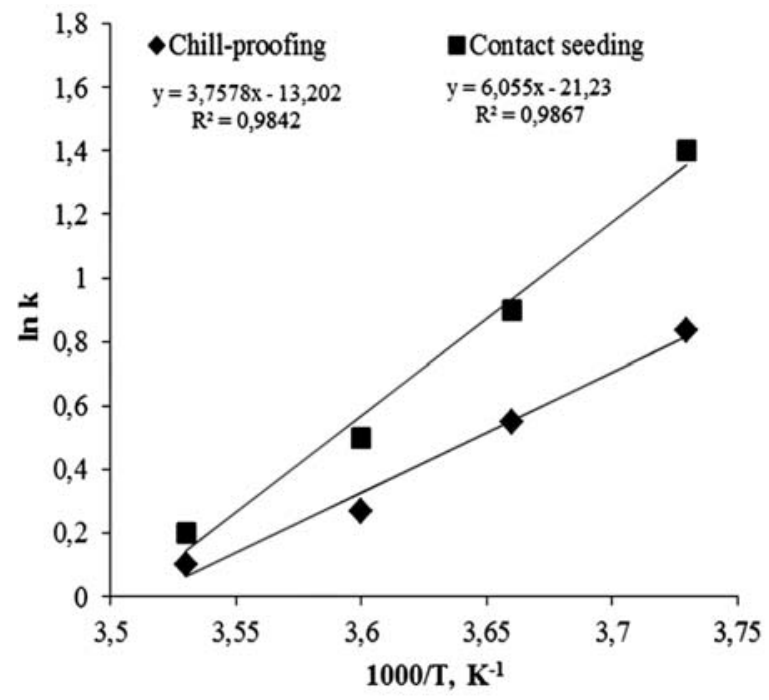

Figure 5. Arrhenius plots of precipitation rate constant for sample 1. 
From the slope of the exposed in Figure 5 dependence, there has been graphically calculated and analytically determined the value of activation energy $\left(E_{a}\right)$ by the relationship (4) and by Eq.(5). The KHT precipitation may be expressed by the Arrhenius Eq.(6) as follows:

$\operatorname{tg} \alpha=\frac{E_{a}}{R}$

$\frac{\ln k_{2}}{\ln k_{1}}=-\frac{E_{a}}{R}\left(\frac{1}{T_{2}}-\frac{1}{T_{1}}\right)$

$\ln k=\ln A-\frac{E_{a}}{R T}$

where: $E_{a}$ - apparent activation energy $\left(\mathrm{kJ} \cdot \mathrm{mol}^{-1}\right)$,

$\operatorname{tg} \alpha$ - tangent of the angle on the dependence $\ln k=\mathrm{f}(1000 / \mathrm{T})$,

$R$ - universal gas constant $\left(8.314 \mathrm{~J} \cdot \mathrm{mol}^{-1} \cdot \mathrm{K}^{-1}\right)$,

$k$ - reaction rate constant at $\mathrm{T}_{2}$ and $\mathrm{T}_{1}\left(\mathrm{~h}^{-1}\right)$,

$A$ - pre-exponential factor or the frequency factor $\left(\mathrm{h}^{-1}\right)$,

$T$ - absolute temperature $(\mathrm{K})$.

As notion, the activation energy $\left(E_{a}\right)$ is the minimum amount of energy that is required for initiation of a chemical reaction, while $A$ represents the frequency of active interaction and can be treated as a constant for a given reacting system over fairly wide temperature range. The results of Arrhenius parameters for the studied samples of wine are listed in Table 5.

According to these data, the value of pre-exponential factor $(A)$ and the values of $E_{a}$ augment with the temperature, due to the exothermic character of the precipitation process. A higher content of tartaric acid and potassium caused highest values of $A$ factor in red wines, as compared to the white ones. Comparative analysis of obtained by different technological schemes wine samples reveals that applied pre-fermentation operations lead to a reduced content of proteins and colloids into wines, which in turn caused the decrease of the activation energy of the studied process. The average values of this reduction constituted $19.14 \%$ for white sample and $23.19 \%$ for red ones, respectively. The values of activation energy were calculated by the analytical and graphical method for the KHT precipitation and the difference of them does not exceed $8 \%$.

Table 5

Value of Arrhenius parameters for KHT precipitation in stabilized by chill-proofing wine samples.

\begin{tabular}{|c|c|c|c|}
\hline Type of wine & $\begin{array}{c}\text { Absolute temperature, } \\
T, K\end{array}$ & $\begin{array}{l}\text { Pre-exponential factor, } \\
\qquad A h^{-1}, 10^{-8}\end{array}$ & $\begin{array}{c}\text { Activation energy, } \\
E_{a}, \mathrm{~kJ} \cdot \mathrm{mol}^{-1}\end{array}$ \\
\hline \multirow{3}{*}{$\begin{array}{c}\text { Sample } 1 \\
\text { of white wine }\end{array}$} & 268 & 7.31 & $74.40 \pm 0.84$ \\
\hline & 273 & 11.21 & $77.28 \pm 0.62$ \\
\hline & 278 & 10.14 & $79.26 \pm 0.78$ \\
\hline \multirow{3}{*}{$\begin{array}{c}\text { Sample } 2 \\
\text { of white wine }\end{array}$} & 268 & 5.31 & $58.09 \pm 0.72$ \\
\hline & 273 & 6.95 & $63.62 \pm 0.91$ \\
\hline & 278 & 10.46 & $65.03 \pm 0.78$ \\
\hline \multirow{3}{*}{$\begin{array}{l}\text { Sample } 3 \\
\text { of red wine }\end{array}$} & 268 & $0.86 \cdot 10^{4}$ & $91.49 \pm 0.88$ \\
\hline & 273 & $2.04 \cdot 10^{4}$ & $97.41 \pm 0.67$ \\
\hline & 278 & $4.28 \cdot 10^{4}$ & $99.08 \pm 0.92$ \\
\hline \multirow{3}{*}{$\begin{array}{l}\text { Sample } 4 \\
\text { of red wine }\end{array}$} & 268 & $2.07 \cdot 10^{3}$ & $68.76 \pm 0.53$ \\
\hline & 273 & $4.15 \cdot 10^{3}$ & $72.77 \pm 0.48$ \\
\hline & 278 & $5.03 \cdot 10^{3}$ & $79.83 \pm 0.80$ \\
\hline
\end{tabular}


The results show that the precipitation reaction of KHT in wine is characterized by medium activation energy and a high frequency factor, which explains the significant reaction rate of these compounds in young white and red wines. In addition, the reaction of KHT precipitation is limited by the kinetics factors, but not by diffusion ones.

\section{Conclusions}

This study on stabilization methods allowed us to obtain the necessary data for explaining physico-chemical phenomena, which influence the stability or instability during young wines stabilization treatments, related to the precipitation of tartaric salts. Kinetic parameters suggested that the KHT precipitation process is influenced by the temperature changes, therefore the increase of temperature leads to a decrease of stabilization process efficiency and an augment of the activation energy in the studied system. The kinetic factors limit the reaction of KHT precipitation, but not the diffusion ones. Also, the pre-fermentative treatments (cryo-maceration of the marc and carbonic maceration of grains) reduce significantly the content of compounds with inhibitory effect on the KHT precipitation. The optimal regime for production and stabilization of young wines was established in economic and technological reasons. The contact seeding is recommended as an efficient method for the tartaric stabilization of young white and red wines.

\section{References}

1. Boiret, M.; Marty, A.; Fabrega, C.; Guittard, A.; Tixier, A.; Schaeffer, A.; Schlewltz, A. Tartaric stability index of wines and the risk of precipitation. Revue Française d'Oenologie, 1991, 128, pp. 53-58 (in French).

2. Vallée, D.; Bagard, A.; Blay, C.; Bourde, L. Tartaric stability assessment of wines by the saturation temperature influence of time factor on stability. Revue Française d'Oenologie, 1990, 126, pp. $51-61$ (in French).

3. Cotea, V. D.; Zănoagă, C.; Cotea, V.V. Treaty of oenochimie. Romanian Academy: Bucharest, 2009, 750 p. (in Romanian).

4. Covaci E.; Duca Gh.; Sturza R. The influence of applied stabilization method on the crystalline stability of young white wines. Chemistry Journal of Moldova, 2013, 8(2), pp. 73-77.

5. Maujean, A. Artificial cold treatment of wines in relation to their stabilization against the crystalline tartaric troubles. In: Recent acquisitions in the physical treatment of the wine. Lavoisier Tec \& Doc:Paris, 1994, 830 p. (in French).

6. Novak, J.; Labik, St.; Malijevsky, A. Physical chemistry in brief. Institute of Chemical Technology: Prague, 2005, 466 p., http://www.old.vscht.cz/fch/en/tools/breviary-online.pdf

7. Maujean, A.; Sausy, L.; Vallee, D. Determination of potassium bitartrate supersaturation of a wine. Quantification of protective colloids effects. Revue Française d'Oenologie-cahier scientifique, 1985, 100(4), pp. 39-49 (in French).

8. Gerbaud, V.; Gabas, N.; Blouin, J.; Pellerin, P.; Moutounet, M. Influence of wine polysaccharides and polyphenols on the crystallisation of potassium hydrogen tartrate. Journal International des Sciences de la Vigne et du Vin, 1997, 31(2), pp. 65-83 (in French).

9. Rhein, O.; Nersdt, F. Tartrate stabilization by the contact process. American Journal of Enology and Viticulture, 1997, 4, pp. 265-266.

10. Covaci E. Thermodynamic parameters of potassium bitartrate during the young wines cold stabilization. Chemistry Journal of Moldova, 2015, 10(1), pp. 41-44.

11. Puig-Deu, M.; López-Tamames, E.; Buxaderas, S.; de la Torre-Boronat, M. Quality of base and sparkling wines as influenced by the type of fining agent added pre-fermentation. Food Chemistry, 1999, 66, pp. 35-42.

12. Marangon, M.; Pocock, K.; Waters, E. The addition of bentonite at different stages of white winemaking and its effect on protein stability. Australian \& New Zealand Grapegrower \& Winemaker, 2012, pp. 71-73.

13. Vidal, J. Vinification technique by carbonic maceration of grapes and its installation. EP Patent, 1987, No. 0217683 A1 (in French).

14. Droux, F.; Vialatte, C. The study of tartaric precipitation in wines using "mini-contact" procedure. Revue d'Oenologie, 1983, 29, pp. 13-14 (in French).

15. Bentonita oenological (Bentonit super), http://www.protectvit.ro/cumpara/bentolit-super-bentonita-sodica/Super. htm.

16. Gelatin oenological de tip Pulviclar S, http://shop.carolinawinesupply.com/Pulviclar/PulS1.htm.

17. International Organisation of Vine and Wine. International Code of Oenological Practices. Official Edition, Paris, 2012, 298 p. (in French).

18. Zarrouk, A.; Hammouti, B.; Zarrok, H.; Al-Deyab, S.S.; Messali, M. Temperature effect, activation energies and thermodynamic adsorption studies of L-cysteine methyl ester hydrochloride As Copper Corrosion Inhibitor In Nitric Acid 2M. International Journal of Electrochemical Science, 2011, 6, pp. 6261-6274.

19. Cruz, C.; da Costa, A.; Henriques, A. Kinetic modeling and equilibrium studies during cadmium biosorption by dead Sargassum sp. Biomass. Bioresource Technology, 2004, 91, pp. 249-257.

20. Agresti, A.; Yongyi, M. On small-sample confidence intervals for parameters in discrete distributions. Biometrics, 2001, 57(3), pp. 963-971.

21. Jäntschi L. Presentation and processing of the experimental data. UTPress: Cluj-Napoca, 2013, 70p. http://www. lori.academicdirect.org/books/press/PPDE_total.pdf (in Romanian). 